\title{
KONTRARADIKALISME: PERSPEKTIF KURIKULUM PAI
}

\author{
Tomi Azami \\ Universitas Pancasakti Tegal \\ Email: tomiazami@upstegal.ac.id
}

\begin{abstract}
Various forms of violence, both physical and verbal in the name of religion, are still rife in Indonesia. Minority communities are often victims. Seeing this, not only repressive measures were carried out, but preventive efforts were needed to overcome this problem. The curriculum should be developed towards counter radicalism. This article is the result of library research or literature research. Collecting data is in the form of library data in the form of books, manuscripts, journals, and other documentation sources.

The results showed preventive efforts in carrying out counterradicalism through education. Education can be a weapon in countering radicalism. Its practical level is reflected in the developed PAI curriculum. Things that need to be underlined are that the definition of the curriculum has a broad range (objectives, materials, strategies, media, and evaluation), intraculricular and extracurricular activities.
\end{abstract}

Key words: Counter Radicalism, Curriculum, PAI

\section{Abstrak}

Beragam kekerasan baik fisik maupun verbal mengatasnamakan agama masih marak di Indonesia. Masyarakat minoritas kerap menjadi korban. Melihat hal tersebut, tidak hanya represif yang dilakukan, namun perlu upaya preventif untuk mengatasi permasalahan ini. Kurikulum sebaiknya dikembangkan ke arah kontraradikalisme. Artikel ini merupakan hasil penelitian kepustakaan atau riset literatur, Pengumpulan data berupa data-data kepustakaan baik berupa buku, manuskrip, jurnal, maupun sumber-sumber berbentuk dokumentasi lainnya.

Hasil penelitian menunjukkan upaya preventif dalam melakukan kontraradikalisme melalui jalur pendidikan. Pendidikan dapat menjadi senjata dalam mengonter radikalisme. Tataran praktisnya tercermin pada kurikulum PAI yang dikembangkan. Hal yang perlu digarisbawahi adalah definisi kurikulum memiliki jangkauan yang luas (tujuan, materi, strategi, media, dan evaluasi), kegiatan intrakulikuler dan ekstrakulikuler.

Kata Kunci: Kontraradikalisme, Kurikulum, PAI 


\section{A. PENDAHULUAN}

Radikalisme masih menjadi persoalan serius di Indonesia. Perusakan rumah ibadah, penolakan terhadap kelompok yang berbeda, dan beberapa bom bunuh diri adalah beberapa kasus yang menyita perhatian pubik. Kasus-kasus seperti ini menjadi bukti nyata bahwa gerakan radikalisme berbalut agama masih terus bermunculan.

Kejadian yang cukup memprihatinkan muncul dari SMK Negeri di Padang yang mewajibkan siswinya memakai jilbab, padahal siswi tersebut non-Islam. kejadian ini sempat memunculkan kehebohan di Indonesia. Pihak sekolah berdalih itu adalah aturan sekolah. Argumen orangtua siswi tersebut anaknya tidak memeluk agama Islam dan sekolah tersebut berstatus negeri. Namun pihak sekolah menghendaki tetap mewajibkan semua peserta didiknya memakai jilbab. ${ }^{1}$

Survei dari Setara Institut terhadap pelajar SMA di Jakarta dan Bandung tahun 2015 menyatakan 16,9\% menganggap ISIS adalah pejuang pendiri Negara Islam. Survei Wahid Foundation tahun 2016 menunjukkan sekitar 11,5 juta dari 150 juta muslim Indonesia berpotensi bertindak radikal dan 600 ribu orang pernah terlibat. ${ }^{2}$ Lembaga Kajian Islam dan Perdamaian (LaKIP) Jakarta merilis 48,9\% siswa Jabodetabek menyatakan persetujuannya terhadap aksi radikal. ${ }^{3}$

Paham radikalisme dan terorisme terselip menjadi konten dalam materi ajar buku mata pelajaran agama. Buku paket dan LKS bermunculan berbagai pernyataan yang dapat mendorong siswa membenci dan anti terhadap agama dan bangsa lain. Sikap ini menjadi salah satu akar paham radikalisme di kalangan umat Islam. ${ }^{4}$

\footnotetext{
${ }^{1}$ Perdana Putra, "Siswi SMK Negeri di Padang Wajib Pakai Jilbab, Orangtua Protes dan Datangi Sekolah," diakses pada 25 Januari 2021, https://regional.kompas.com/read/2021/01/22/20422781/siswi-smk-negeri-di-padang-wajibpakai-jilbab-orangtua-protes-dan-datangi

${ }^{2}$ Rakhmat Nur Hakim, "Survei Wahid Foundation: Indonesia Masih Rawan Intoleransi dan Radikalisme," diakses pada 5 Januari 2017, http://nasional.kompas.com/read/2016/08/01/13363111/survei.wahid.foundation.indonesia. masih.rawan.intoleransi.dan.radikalisme?page=all.

3 Abdul Munip, "Menangkal Radikalisme Agama Di Sekolah", Jurnal Pendidikan Islam 2 (2012), 160, diakses 5 Januari 2017, doi: 10.14421/jpi.2012.12.159-181.

${ }^{4} \mathrm{Abu}$ Rokhmad, "Radikalisme Islam dan Upaya Deradikalisasi Paham Radikal", Jurnal Walisongo $20 \quad$ (2012), 109, diakses 5 Januari 2017, doi:http://dx.doi.org/10.21580/ws.2012.20.1.185.
} 


\section{Jurnal Pendidikan Agama Islam Universitas Wahid Hasyim Semarang}

Berbagai kasus di atas menunjukkan bahwa isu radikalisme masih perlu ditangani dengan serius. Tidak hanya dalam tataran hukum yakni menangkap para pelaku gerakan radikalisme. Namun perlu upaya penanganan radikalisme sampai pada tataran preventif.

Pendidikan Agama Islam (PAI) sebagai mata pelajaran dengan muatan agama bisa menjadi benteng kuat di sekolah dalam melawan radikalisme. Sekolah dapat mendesain dan mengembangkan kurikulum PAI untuk melawan radikalisme. Pemahaman radikalisme dikonter dengan pemahaman agama yang ramah dan rahmatan lil alamin.

\section{B. METODE PENELITIAN}

Metode penelitian pada artikel ini berjenis Qualitative Research dengan penelitian kepustakaan (librabry research). Penelitian kepustakaan melalui riset kepustakaan yang berdasarkan pustaka yakni sumber utamanya berupa data-data kepustakaan berupa buku, manuskrip, kitab-kitab, maupun sumber-sumber lain yang berupa dokumentasi lainnya. Ada dua sumber pokok dalam penelitian ini, yakni sumber primer dan sekunder. Sumber primer yang dimaksud dalam penelitian ini adalah buku-buku tentang radikalisme dan kurikulum, sedangkan sumber sekunder di sini adalah sumber kedua yang bersifat menunjang sumber data primer. Dalam hal ini menggunakan jurnal penelitian, majalah, koran, dan lain sebagainya.

\section{HASIL DAN PEMBAHASAN}

\section{Sekilas tentang Radikalisme}

Secara terminologi, radikalisme memiliki arti paham atau aliran dalam politik. Paham atau aliran yang menginginkan perubahan atau pembaharuan sosial dan politik dengan cara kekerasan atau drastis. Sikap ekstrem dalam aliran politik. ${ }^{5}$ Syamsul Ma'arif menyebut radikalisme memiliki arti sebuah paham atau aliran yang sering berpandangan kolot, bertindak dengan menggunakan kekerasan

${ }^{5}$ Badan Pengembang dan Pembinaan Bahasa Kementerian Pendidikan dan Kebudayaan Republik Indonesia, KBBI Edisi V, 2016, Aplikasi android versi 0.1.5 Beta. 
dan bersifat ekstrem untuk merealisasikan cita-citanya. ${ }^{6}$ Yusuf al-Qaradhawi, menyebut radikalisme dengan istilah al-Tatarruf ad-Din. ${ }^{7}$ Jadi paham ini lebih ke pemaksaan bahkan kekerasan dalam upaya melaksanakan perubahan atau mengajarkan keyakinan yang dianut.

Ada kesimpangsiuran penggunaan istilah antara radikalisme dengan fundamentalisme. Ada yang memaknai radikalisme dalam tataran pikiran, terkadang bermaksud untuk menunjuk kelompok pengembali (revivalis) Islam. Namun terkadang istilah fundamentalis juga ditujukan untuk menyebut gerakan radikalisme Islam dan terorisme. Gerakan fundamentalisme ini memiliki dampak ke ranah politik yang membahayakan negara-negara industri di Barat. ${ }^{8}$ Harun Nasution menyebut fundamentalisme adalah kembali ke ajaran-ajaran dasar agama, yakni Al-Qur'an dan Hadits, serta mengindahkan ajaran-ajaran hasil ijtihad ulama seperti tafsir, fikih, ilmu tauhid, tasawuf, dan lain sebagainya. ${ }^{9}$

Memiliki berbagai pendapat di atas, pada tulisan ini, untuk merujuk kekerasan yang mengatasnamakan agama penulis lebih condong menggunakan istilah radikalisme daripada fundamentalisme. Hal ini karena pengertian fundamentalisme dapat memiliki arti lain yang terkadang mengaburkan makna kekerasan. Sementara radikalisme dianggap memiliki makna yang lebih jelas, yakni gerakan yang menggunakan kekerasan untuk mencapai target politik yang ditopang oleh sentimen atau isu keagamaan.

Azyumardi Azra dalam Thohir menegaskan akar radikalisme itu setidaknya bersumber dari empat hal, yaitu: ${ }^{10}$

${ }^{6}$ Syamsul Ma'arif, "Ideologi Pesantren Salaf: Deradikalisasi Agama dan Budaya Damai," Ibda' Jurnal Kebudayaan Islam 12 (2014):200, diakses 3 April 2017, doi: http://dx.doi.org/10.24090/ibda.v12i2.2014.pp198-209. Pendapat sama diutarakan Rahimi Sabirin, Islam dan Radikalisme, dalam Sahri, "Radikalisme Islam di Perguruan Tinggi Perspektif Politik Islam," Al-Daulah: Jurnal Hukum dan Perundangan Islam 6, (2016): 242.

${ }^{7}$ Yusuf al-Qardhawi, al-Sahwah al-Islamiyyah: Baina al-Juhad wa al-Tatarruf, (Qatar: Al-Ummah, $1402 \mathrm{H}), 23-24$.

${ }^{8}$ Kuntowijoyo, Identitas Politik Umat Islam, (Bandung: Mizan, 1997), 49

${ }^{9}$ Harun Nasution, Islam Rasional, (Bandung: Mizan, 1996), 122.

${ }^{10}$ Muhammad Thohir, "Radikalisme Versus Pendidikan Agama Menggali Akar Radikalisme Dari Kekerasan Terhadap Anak Atas Nama Pendidikan Agama," Nadwa Jurnal 
a. pemahaman keagamaan sempit, literal, dan sepenggal-sepenggal terhadap ayat-ayat al-Qur'an

b. bacaan yang salah terhadap sejarah Islam yang dikombinasikan dengan idealisasi berlebihan terhadap Islam pada masa tertentu

c. argumentasi deprivasi politik, sosial dan ekonomi yang masih bertahan dalam masyarakat, dan

d. disorientasi dan dislokasi sosial budaya akibat globalisasi.

Bassam Tibi menyebut radikalisme Islam muncul bukan persoalan teologis, melainkan fenomena politik. Kelompok radikalis sering menggunakan kata jihad sebagai pembenar. Tibi membedakan istilah "jihad" dan "jihadism". Tibi menyebut istilah jihad muncul pada zaman Rasulullah SAW yang memiliki arti perang dengan aturan yang jelas seperti tidak membunuh anak-anak atau warga sipil. Sedangkan istilah "jihadism" dimaknai hanya perang, pertempuran fisik, dan teror yang tidak ada aturan dan batasan serta dibumbui faktor politik keagamaan. ${ }^{11}$ "Jihadism" sudah tidak relevan dengan zaman Rasulullah. Kekerasan yang mengatasnamakan jihad sejatinya bukan bagian dari Islam. Umat Islam Indonesia terkadang melihat fenomena radikalisme menjadi bagian perintah Islam dalam bentuk jihad.

\section{Radikalisme sebagai Sebuah Gerakan}

Merujuk definisi di atas, sejatinya radikalisme tidak menjadi masalah, dengan catatan selama dalam bentuk pemikiran dalam diri penganutnya. Namun ketika radikalisme bergeser ke wilayah gerakan, di sinilah timbul masalah. Terutama ketika semangat untuk kembali pada dasar agama terbentur kekuatan politik lain. Dalam situasi ini, tidak jarang radikalisme akan diiringi kekerasan atau terorisme.

Menurut Hasan dan Naipospos, radikalisme terbagi menjadi dua dimensi, yaitu paham dan gerakan. Radikal dalam paham diartikan pemikiran untuk mendirikan negara Islam, kekhalifahan Islam, tanpa menggunakan kekerasan.

\footnotetext{
Pendidikan Islam 9 (2015): 175, diakses 5 Januari 2017, doi: http://dx.doi.org/10.21580/nw.2015.9.2.521.

${ }^{11}$ Bassam Tibi, Islamism and Islam, (London: Yale University Press, 2012), PDF ebook, bab 5 .
} 
Radikal dalam gerakan diartikan melakukan perubahan dengan aksi-aksi kekerasan atas nama agama. ${ }^{12}$ Ma'arif menyebut radikalisme dalam pikiran sering disebut fundamentalisme, dan radikalisme dalam tindakan menghalalkan caracara kekerasan kerap disebut terorisme. ${ }^{13}$

Endang Turmudi membagi radikalisme dalam 3 bentuk: pertama, gerakan yang sekadar memperjuangkan implementasi syari'at Islam tanpa harus mendirikan negara Islam, cenderung menggunakan cara atau pendekatan kekerasan, yaitu FPI dan Laskar Jihad. Kedua, kelompok yang memperjuangkan berdirinya Negara Islam Indonesia (NII). Ketiga, kelompok yang ingin mewujudkan kekhalifahan Islam dengan syariat Islam sebagai dasarnya, kelompok ini diwakili gerakan Hizbut Tahrir Indonesia (HTI) dan Majelis Mujahidin Indonesia (MMI). ${ }^{14}$

Menurut Qodir, radikalisme sebagai gerakan dapat dibagi menjadi tiga kategori, yaitu jihadis, reformis, dan rejeksionis. Jihadis adalah bentuk aksi politik berupa tindakan kekerasan atas nama jihad. Reformis adalah bentuk aksi politik tanpa kekerasan yang akan mengganggu stabilitas nasional. Rejeksionis adalah aksi politik berupa penolakan terhadap sistem demokrasi dan melakukan tekanantekanan terhadap berbagai kebijakan. ${ }^{15}$

Radikalisme sebagai gerakan diidentifikasikan sebagai berikut: ${ }^{16}$

a. Kelompok radikalis sering menunjukkan mental Perang Salib dalam konteks sekarang. Mereka menganggap hegemoni barat sebagai bentuk penjajahan.

b. Penegakan hukum Islam yang kerap menggunakan kekerasan.

c. Terdapat kecenderungan melakukan perlawanan terhadap pemerintahan dan sistem yang ada karena dianggap tidak sah.

\footnotetext{
${ }^{12}$ Ismail Hasani dan Bonar Tigor Naipospos, Dari Radikalisme Menuju Terorisme: Studi Relasi dan Transformasi Organisasi Islam Radikal di Jawa Tengah \& D.I. Yogyakarta, (Jakarta: SETARA Institute, 2012), 11.

${ }^{13}$ Ma'arif, "Ideologi Pesantren Salaf," 201.

${ }^{14}$ Endang Turmudi, Islam dan Radikalisme di Indonesia (Jakarta: LIPI Press, 2005), 5.

${ }^{15}$ Zuly Qodir, Radikalisme Agama di Indonesia, (Yogyakarta: Pustaka Pelajar, 2014), 27.

${ }^{16}$ Abuddin Nata, Studi Islam Komprehensif, (Jakarta: Kencana, 2011), 503
} 
d. Sentimen Yahudi-Palestina membawa pada pertikaian Islam-Kristen di beberapa wilayah.

Radikalisme sering dikaitkan dengan agama padahal belum tentu. Amin Abdullah dalam Mulyani Mudis Taruna menyatakan dalam kelompok Islam garis keras atau Islam radikal adalah sikap mental untuk mengadakan perlawanan yang dilakukan oleh setiap individu dan kelompok yang dianggap sebagai lawan dalam fikih, sosial, dan akidah. Sikap sosial sebagian kelompok garis keras sangat dipengaruhi oleh ayat-ayat Al-Qur'an yang tidak multikultural. ${ }^{17}$

Masdar Hilmy memaparkan beberapa karakteristik paham keagamaan Islam radikal: (1) Menghendaki pelaksanaan hukum Islam dalam semua tataran kehidupan, puncaknya adalah pendirian "negara Islam". (2) Menafsirkan ayatayat Al-Qur'an secara literal tekstualis tanpa melihat konteks sejarah yang terjadi saat ayat tersebut turun. (3) Penggunaan simbol secara dominan. (4) Memandang segala sesuatu dengan dua dimensi, benar dan salah, hitam dan putih, reward dan punishment, halal dan haram. (5) Mengisolir diri (eksklusif) dari pengaruh luar. ${ }^{18}$

\section{Kurikulum: definisi dan ruang lingkup}

Kurikulum dari kata curir atau curere, yang diartikan jarak yang harus ditempuh oleh seorang pelari. Kata "curriculum" berasal dari bahasa Latin yang artinya "racecourse", yakni "the relatively standardized ground covered by students in their race toward the finish line." Kata "curere" yang berasal dari bahasa Latin lebih bermakna "running of the race" daripada "racecourse". 19

Nasution dalam Hamalik membedakan pengertian kurikulum menjadi dua, yakni tradisional dan modern. Dalam arti tradisional, kurikulum merupakan sejumlah mata pelajaran di sekolah atau di perguruan tinggi yang harus ditempuh

${ }^{17}$ Mulyani Mudis Taruna, "Pondok Pesantren Ittiba'us Sunnah Klaten; Antara Radikalisme dan Semangat Kebangsaan", dalam Radikalisme dan Kebangsaan Kelompok Keagamaan Perspektif Pendidikan, Siti Muawanah dkk, (Yogyakarta: Arti Bumi Intaran, 2016), 43

${ }^{18}$ Masdar Hilmy, "The Politics of Retaliation: The Backlash of Radical Islamists to Deradicalization Project in Indonesia,"Al-Jami 'ah Journal of Islamic Studies, 51 (2013): 133136, diakses pada 112 Oktober 2017, doi: 10.14421/ajis.2013.511.129-158.

${ }^{19}$ Abdul Rohman, Pengembangan Kurikulum Teori dan Praktik, 60. 
untuk mendapatkan ijazah atau naik tingkat. Sedangkan dalam arti modern kurikulum merupakan pengalaman, kegiatan, dan pengetahuan peserta didik baik di kelas atau di luar selama dalam bimbingan dan tanggung jawab sekolah atau guru. $^{20}$

Hamalik menyebut pengertian dalam arti modern membawa implikasi tafsiran kurikulum secara luas. Kurikulum tidak hanya dimaknai sebatas mata pelajaran yang dipelajari di dalam kelas, namun menyangkut kegiatan dan pengalaman di luar sekolah yang dikenal dengan istilah ekstrakulikuler juga termasuk dalam pengertian kurikulum. ${ }^{21}$ Kurikulum menurut Saylor dan Alexander dalam Oliva, "The school curriculum is the total effort of the school to bring about desired outcomes in the school and in out of school situation. The curriculum is the sum total of the school's efforts to influence learning, whether in the classroom, on the playground or out of school. $" 22$

Raihani memberi definisi "Curriculum is a set of experiences that students undertake with the guidance of the school, in order to achieve the goals of their school". ${ }^{23}$ Deighton berpendapat: "Curriculum includes the goals, objectives, content, processes, resources, and mean of evaluation of all the learning experiences planed for pupils both in and out of the school and community through classroom instruction and related program for example, field trips, library program, work experience education, guidance, and extra classroom activities" ${ }^{24}$

Omar Mohammad al-Toumy al-Syaibany menyebut kurikulum sebagai manhaj atau jalan terang yang dilalui pendidik dengan orang-orang yang dididik untuk mengembangkan pengetahuan, keterampilan, dan sikap mereka. ${ }^{25}$ Jalan

${ }^{20}$ Oemar Hamalik, Dasar-dasar Pengembangan Kurikulum, (Bandung: Remaja Rosdakarya, 2016), 3-5.

${ }^{21}$ Hamalik, Dasar-dasar Pengembangan Kurikulum, 5.

${ }^{22}$ Peter F. Oliva, Developing the Curriculum, (New York: Harper Collins, 1992), 6.

${ }^{23}$ Raihani, Curriculum Constructionin the Indonesian Pesantren, (Berlin: Lambert Academic Publishing, 2010), 12.

${ }^{24}$ Lee C. Deighton, The Encyclopedia of Education, vol. 2, (New York: The Macmillan Company \& The Free Press, 1971), 564.

${ }^{25}$ Omar Mohammad al-Toumy al-Syaibany, Falsafah Pendidikan Islam, terj. Hasan Langgulung, (Jakarta: Bulan Bintang, 1975), 478. 
terang yang dimaksud dalam bidang pendidikan meliputi semua unsur proses pendidikan dan unsur rencana pendidikan yang diikuti oleh pendidik dalam mengajar dan mendidik peserta didiknya. ${ }^{26}$ Sementara Mahfud Junaedi menyebut kurikulum terdiri dari 4 komponen: 1) tujuan, 2) isi, 3) metode atau proses belajar mengajar, dan 4) evaluasi. ${ }^{27}$

Dari berbagai penjelasan di atas dapat disimpulkan bahwa kurikulum adalah alat penting untuk mencapai tujuan sekolah melalui program-program yang telah dirancang. Program-program tersebut berisi konten dan pengalaman yang diberikan secara bertahap pada peserta didik dalam bimbingan guru dan pihak sekolah. Kurikulum tidak sebatas hanya tertulis dalam dokumen tapi mencakup segala kegiatan yang terjadi baik di dalam atau di luar kelas seperti pertunjukan drama, pertandingan olahraga, dan kemampuan baris berbaris asalkan masih dalam naungan sekolah.

\section{Peran Guru dalam Kurikulum}

Guru menjadi faktor penting dalam menentukan apakah kurikulum berhasil atau tidak. Guru adalah aktor utama perubahan kurikulum, tetapi tidak hanya guru seorang yang memegang peranan penting. Elemen luar sekolah seperti masyarakat, orangtua, persatuan guru, dan lain-lain juga turut andil. Perubahan kurikulum mencakup pula perubahan sistem sosial sekolah, bersamaan individu guru, karena suatu perubahan akan berdampak pada warga sekolah lain.

Ansyar menyebut alasannya karena penerapan kurikulum mengubah kebiasaan, persepsi, metode pengajaran, dan praktik pendidikan yang sudah rutin dilakukan guru di sekolah. ${ }^{28} \mathrm{Jadi}$, dalam menerapkan sebuah kurikulum diperlukan kerjasama antara individual dan kelompok sosial sekolah. Mempertimbangkan peran guru dalam kurikulum penting dilakukan.

\footnotetext{
${ }^{26} \mathrm{Al}$-Syaibany, Falsafah Pendidikan Islam, 488.

${ }^{27}$ Mahfud Junaedi, Filsafat Pendidikan Islam: Dasar-dasar Memahami Hakikat Pendidikan Perspektif Islam, (Semarang: CV Karya Abadi Jaya, 2015), 217.

${ }^{28}$ Mohammad Ansyar, Kurikulum Hakikat, Fondasi, Desain, dan Pengembangan, (Jakarta: Kencana, 2015), 424.
} 
Keberhasilan kurikulum semakin terbuka jika dilakukan melalui perencanaan yang mempertimbangkan guru sebagai bagian penting perubahan sekolah. ${ }^{29}$

Di tangan gurulah kurikulum dijabarkan, dikembangkan, diperluas, sehingga dapat ditransformasikan kepada siswa dalam pembelajaran. Melalui kepiawaian guru, kurikulum memiliki makna dan nilai. Artinya, melalui guru nilai yang terkandung dan aktualisasi serta transformasi nilai-nilai, sikap, pengetahuan, dan keterampilan dalam kurikulum dapat disampaikan kepada siswa.

Syafruddin Nurdin dan Andriantoni menyatakan seberapapun bagusnya kurikulum (official) hasil sangat tergantung apa yang dilakukan oleh guru dan siswa dalam kelas (aktual). Salah satu indikator keberhasilan guru dan dosen adalah terwujudnya kurikulum ideal (potensial, official curriculum) menjadi kurikulum aktual (real curriculum) dalam pembelajaran di kelas. ${ }^{30}$

\section{Kurikulum sebagai Senjata Melawan Radikalisme}

Melihat isu radikalisme yang menjadi persoalan genting perlu adanya respon sebagai upaya melakukan counter terhadap radikalisme. Jonathan Stevenson memberikan beberapa strategi dalam merespon munculnya radikalisme, sebagai berikut: (1) Jalur militer, military of counter terrorism. (2) Menggunakan counters argument. (3) Menggunakan model peningkatan kesejahteraan. (4) Melakukan persebaran gagasan perdamaian dunia. ${ }^{31}$

Mengacu pada pendapat Stevenson di atas, upaya melawan radikalisme bisa menggunakan counter argument. Upaya ini bisa diejawantahkan melalui pendidikan. Pendidikan menjadi problem solver vital dalam menghadapi isu radikalisme mengatasnamakan agama. Counter argument ini sangat penting dilakukan oleh lembaga pendidikan sebagai upaya membangun pemahaman kontra radikalisme agama kepada peserta didik. Counter argument dapat dengan cara transfer nilai-nilai Islam yang moderat, ramah, dan sejuk melalui kurikulum

\footnotetext{
${ }^{29}$ Mohammad Ansyar, Kurikulum Hakikat, Fondasi, Desain, dan Pengembangan, 424.

${ }^{30}$ Syafruddin Nurdin dan Andriantoni, Kurikulum dan Pembelajaran, (Jakarta: Rajawali Press: 2016), 62.

${ }^{31}$ Jonathan Stevenson, "Counter-Terrorist Strategies," dalam Radical Islam and International Security, Hillel Frisch dan Efraim Inbar, (London: Routledge, 2008), PDF ebook, bab 12 .
} 
Pendidikan Agama Islam (PAI) yang dirancang dan dikembangkan ke arah tersebut. Tidak lagi menampilkan Islam yang keras, eksklusif, dan lekat dengan mengangkat senjata.

Wajah Islam yang humanis diperkenalkan kepada masyarakat melalui pendidikan. Islam yang ingin mengintegrasikan nilai-nilai kemanusiaan seperti kasih sayang, rasa cinta, persaudaraan, perdamaian, toleransi, dan keselamatan bersama dalam berbagai aspek kehidupan, yakni kegiatan politik pemerintahan, hukum, pelestarian lingkungan, kegiatan bisnis, sosial kemasyarakatan, dan hubungan antara umat beragama. ${ }^{32}$

Melalui Islam humanis, masyarakat Islam diingatkan saat menangani berbagai masalah lebih mengedepankan cara-cara yang halus, santun, manusiawi, dan toleran. Jadi tidak selalu yang muncul ke permukaan adalah wajah Islam yang garang, tetapi juga Islam memiliki sisi yang lembut.

Kurikulum erat kaitannya dengan lembaga pendidikan terutama melalui para pendidik dan stakeholder memberikan pemahaman yang komprehensif pada peserta didik tentang berbagai pengetahuan, sikap, dan tindakan kontra radikalisme. Perlu pemahaman mengenai keragaman agama dan keragaman pemikiran dalam tubuh Islam adalah realitas sunnatullah. Melalui kurikulum yang memuat kontraradikalisme, peserta didik diberi pemahaman mengenai kebenaran relatif, menerima perbedaan, membiasakan dialog, dan tidak memaksakan kehendak.

Pemikiran Pierre Bourdieu sebagaimana dijelaskan David Swartz bisa menjadi landasan lembaga pendidikan dalam mengembangkan kurikulum kontra radikalisme, yakni mengenai habitus (kebiasaan), capital (modal), dan field (arena). Bourdieu mengemukakan bahwa antara tiga elemen habitus, capital, dan field harus berhubungan secara timbal balik dan hubungan yang bersifat dialektikal. ${ }^{33}$

${ }^{32}$ Abuddin Nata, Studi Islam Komprehensif, 513.

${ }^{33}$ David Swartz, Culture and Power the Sociology of Pierre Bourdieu, (London: The University of Chicago Press, 1997), PDF e-book, bab 6. 
Sebagai sebuah arena, dalam hal ini sekolah -yang juga termasuk komponen kurikulum- tentu sangat penting diperhatikan sebagaimana pemikiran Pierre Bourdieu mengenai habitus. Habit (kebiasaan) akan muncul ketika ada capital (modal) dan arena secara perlahan-lahan akan menjadi praktik dalam kehidupannya. Jika modalnya adalah kontraradikalisme, dan mendapatkan arena yang kondusif, moderat, maka yang akan lahir adalah pemikiran moderat, ramah, dan penuh cinta yang kuat. Arena dan modal akan sangat berpengaruh pada pembentukan habitus/kebiasaan peserta didik.

Hal itu berarti jika modal sosial kontra radikalisme tersebut terus berlangsung, berkembang, dan terpupuk pada peserta didik dalam arena yang sama, maka upaya perlawanan terhadap radikalisme, sebagaimana teori habitus Pierre Bourdieu, akan muncul.

Pendidikan menjadi sarana utama penyebaran sebuah paham atau pemikiran. Tak terkecuali oleh kalangan radikalis yang menjadikan pendidikan sebagai sarana doktrinasi paham yang keliru. Anak dijejali materi tanpa tahu apa makna yang dikandung dan manfaat dari materi tersebut.

Pemberian pemahaman yang sepotong, dan tidak memberi ruang untuk diskusi adalah tanda ada pengekangan. Kaum radikalis hanya menyajikan dalil naqli sebagai dalih tindakan keras yang mereka lakukan direstui dalam Al-Qur'an dan Hadits. Kaum radikalis tidak menampilkan ilmu-ilmu alat terkait cara memahami sebuah dalil sehingga pemahaman mereka berhenti pada apa yang ada dalam teks.

Paul Freire menyebut pendidikan seharusnya membebaskan. Freire melihat selama ini praktik pendidikan itu mengekang, menindas, dan tidak membebaskan. Pendidikan atau sekolah harus kembali pada kebutuhan masyarakat dan realita sosial. Dimulai dari mengubah pola hubungan pendidik dan peserta didik dengan berkolaborasi dan bekerja sama dalam mengembangkan kurikulum. ${ }^{34}$

${ }^{34}$ Paul Freire, Politik Pendidikan Kebudayaan, Kekuasaan, dan Pembebasan, terj. Agung Prihantoro dan Fuad Arif Fudiyartanto, (Yogyakarta: Pustaka Pelajar, 2002), 175. 
Pendidikan yang membelenggu bersifat preskriptif, yakni semata-mata memberi petunjuk atau ketentuan mengenai sesuatu, dan berusaha menanamkan kesadaran yang keliru kepada siswa. Sedangkan pendidikan yang membebaskan bersifat dialogis tidak memaksakan pendapat kepada peserta didik. Ada proses transformasi pemahaman yang diuji dalam kehidupan nyata. ${ }^{35}$

Jika dikaitkan dengan gerakan radikalisme, gerakan ini muncul dari paham yang semata memberi legitimasi dan harus berbuat sesuai dengan teks. Ini dianggap membelenggu jika menilik penjelasan Freire di atas. Hal ini karena tidak adanya dialog mengenai teks. Tidak ada dialog dengan ilmu asbabun nuzul atau tafsir misalnya. Sebagaimana yang diutarakan Qodir, kalangan radikalisme tidak bersedia berdialog dengan pihak lain tentang gagasan mereka. Mereka memaksakan pendapat dan melakukan segala cara agar pendapatnya diterima.

Ketika pendapatnya tidak diterima, muncul istilah takfir (mengkafirkan pihak lain). Mereka yang dianggap kafir wajib diperangi. Inilah bentuk ancaman paling nyata dari radikalisme Islam. Penggunaan istilah takfir menjadi pembenar dalam melakukan tindak kekerasan pada pihak yang berbeda pendapat, ini menjadi sebab munculnya serangkaian bom di berbagai daerah. ${ }^{36}$ Dogma seperti ini yang ditanamkan kepada "calon pengantin", yakni para calon pembawa bom bunuh diri.

Melawan radikalisme dengan menanamkan keseimbangan dalam beragama, penerimaan, dan toleransi dalam umat Islam. Selain itu umat Islam dapat mengimplementasikan nilai-nilai seperti toleransi, moderasi, dan keadilan dalam pola hubungan sosial dengan orang lain. ${ }^{37}$

\section{KESIMPULAN}

Berdasarkan hal tersebut, maka diperlukan pemahaman kontraradikalisme yang dikembangkan dalam kurikulum lembaga pendidikan, khususnya Pendidikan Agama

${ }^{35}$ Freire, Politik Pendidikan Kebudayaan, 176.

${ }^{36}$ Zuly Qodir, Radikalisme Agama di Indonesia, 41.

${ }^{37}$ Alwi Shihab, Islam Inklusif: Menuju Sikap Terbuka dalam Beragama, (Bandung: Mizan, 1999), 257 


\section{Jurnal Pendidikan Agama Islam Universitas Wahid Hasyim Semarang}

Islam. Di dalam kurikulum PAI memuat proses diskusi atau tabayyun dengan peserta didik ketika melihat teks, melihat tafsir, kemudian disesuaikan dengan konteks sekarang. Konsep ini bisa terealisasi melalui kurikulum yang dikembangkan ke arah moderasi. Tentu dengan definisi kurikulum yang luas.

Peserta didik mendapatkan pemahaman yang lebih komprehensif dan moderat tentang tema yang berkaitan dengan radikalisme, misalnya ayat tentang jihad. Melalui proses ini ada pemahaman secara menyeluruh yang diterima peserta didik. Tujuan yang hendak dicapai tidak ada lagi saling mengafirkan dan klaim kebenaran dari salah satu kelompok. Munculnya sikap toleransi dan moderasi dari peserta didik dalam melihat realitas masyarakat yang berbeda-beda.

Guru berhadapan langsung dengan peserta didik diharapkan bisa memberikan pemahaman yang komprehensif tentang Islam. Islam menghendaki umatnya mengambil jalan tengah dalam memahami teks. Islam melarang kekerasan, kekakuan, kebekuan dan fanatisme berlebih dalam beragama. 


\section{DAFTAR PUSTAKA}

al-Qardhawi, Yusuf. al-Sahwah al-Islamiyyah: Baina al-Juhad wa al-Tatarruf. Qatar: Al-Ummah, $1402 \mathrm{H}$.

al-Syaibany, Omar Mohammad al-Toumy. Falsafah Pendidikan Islam, terj. Hasan Langgulung. Jakarta: Bulan Bintang, 1975.

Ansyar, Mohammad. Kurikulum Hakikat, Fondasi, Desain, dan Pengembangan. Jakarta: Kencana, 2015.

Azra, Azyumardi. Pergolakan Politik Islam: dari Fundamentalisme, Modernisme, hingga Post-Modernisme. Jakarta: Paramadina, 2006.

Beane, James A. Curriculum Integration Designing the Core of Democratic Education. New York Teachers College Press, 1997.

Drake, Susan M. Menciptakan Kurikulum Terintegrasi yang Berbasis Standar, terj. Benyamin Molan. Jakarta: Indeks, 2013.

Freire, Paul. Politik Pendidikan Kebudayaan, Kekuasaan, dan Pembebasan, terj. Agung Prihantoro dan Fuad Arif Fudiyartanto. Yogyakarta: Pustaka Pelajar, 2002.

Hamalik, Oemar, Dasar-dasar Pengembangan Kurikulum. Bandung: Remaja Rosdakarya, 2016.

Hasani, Ismail dan Bonar Tigor Naipospos. Dari Radikalisme Menuju Terorisme: Studi Relasi dan Transformasi Organisasi Islam Radikal di Jawa Tengah \& D.I. Yogyakarta. Jakarta: SETARA Institute, 2012.

Hilmy, Masdar, "The Politics of Retaliation: The Backlash of Radical Islamists to Deradicalization Project in Indonesia," Al-Jami'ah Journal of Islamic Studies, 51 (2013): 129-158, diakses pada 112 Oktober 2017, doi: 10.14421/ajis.2013.511.129-158.

Idi, Abdullah. Pengembangan Kurikulum: Teori dan Praktik. Yogyakarta: Ar Ruzz Media, 2007.

Junaedi, Mahfud. Filsafat Pendidikan Islam: Dasar-dasar Memahami Hakikat Pendidikan Perspektif Islam. Semarang: CV Karya Abadi Jaya, 2015.

Ma'arif, Syamsul, "Ideologi Pesantren Salaf: Deradikalisasi Agama dan Budaya Damai," Ibda' Jurnal Kebudayaan Islam 12 (2014): 198-209, diakses 3 April 2017, doi: http://dx.doi.org/10.24090/ibda.v12i2.2014.pp198-209.

Muhaimin. Paradigma Pendidikan Agama Islam: Upaya Mengefektifkan Pendidikan Agama Islam di Sekolah. Bandung: Remaja Rosdakarya, 2004.

Munip, Abdul, "Menangkal Radikalisme Agama di Sekolah", Jurnal Pendidikan Islam 2 (2012): 159-181, diakses 5 Januari 2017, doi: 10.14421/jpi.2012.12.159-181. 
Jurnal Pendidikan Agama Islam Universitas Wahid Hasyim Semarang

Nurdin, Syafruddin dan Andriantoni. Kurikulum dan Pembelajaran. Jakarta: Rajawwali Press: 2016

Oliva, Peter F. Developing the Curriculum. New York: Harper Collins, 1992.

Peraturan Menteri Agama Republik Indonesia Nomor 2 Tahun 2008, Standar Kompetensi Lulusan dan Standar Isi Pendidikan Agama Islam dan Bahasa Arab di Madrasah, bab VIII

Pratt, David. Curriculum Design and Development. New York: Harcourt Brace Jovanovich, 1980.

Qodir, Zuly. Radikalisme Agama di Indonesia. Yogyakarta: Pustaka Pelajar, 2014.

Raihani. Curriculum Construction in the Indonesian Pesantren. Berlin: Lambert Academic Publishing, 2010.

Rakhmat Nur Hakim, "Survei Wahid Foundation: Indonesia Masih Rawan Intoleransi dan Radikalisme," diakses pada 5 Januari 2017, http://nasional.kompas.com/read /2016/08/01/13363111 /survei.wahid.foundation.indonesia.masih.rawan.intoleransi.dan.radikalisme ?page $=$ all.

Rokhmad, Abu, "Radikalisme Islam dan Upaya Deradikalisasi Paham Radikal", Jurnal Walisongo 20 (2012): 79-114, diakses 5 Januari 2017, doi:http://dx.doi.org/10.21580/ws.2012.20.1. 185.

Sahri, "Radikalisme Islam di Perguruan Tinggi Perspektif Politik Islam," Al-Daulah: Jurnal Hukum dan Perundangan Islam 6, (2016): 237-268.

Sanjaya, Wina. Kurikulum dan Pembelajaran. Jakarta: Kencana, 2010.

Saylor, J.G dkk. Curriculum Planning for Better Teaching and Learning. New York: Holt Rinehart and Winston, 1981.

Shihab, Alwi. Islam Inklusif: Menuju Sikap Terbuka dalam Beragama. Bandung: Mizan, 1999.

Stevenson, Jonathan. "Counter-Terrorist Strategies," dalam Radical Islam and International Security, Hillel Frisch dan Efraim Inbar. London: Routledge, 2008. PDF e-book, bab 12.

Subandijah. Pengembangan dan Inovasi Kurikulum. Jakarta: Raja Grafindo, 1996.

Swartz, David. Culture and Power the Sociology of Pierre Bourdieu. London: The University of Chicago Press, 1997, PDF e-book, bab 6.

Taruna, Mulyani Mudis. "Pondok Pesantren Ittiba'us Sunnah Klaten; Antara Radikalisme dan Semangat Kebangsaan", dalam Radikalisme dan Kebangsaan Kelompok Keagamaan Perspektif Pendidikan, Siti Muawanah dkk, Yogyakarta: Arti Bumi Intaran, 2016.

Thohir, Muhammad, "Radikalisme Versus Pendidikan Agama Menggali Akar Radikalisme Dari Kekerasan Terhadap Anak Atas Nama Pendidikan 
Agama," Nadwa Jurnal Pendidikan Islam 9 (2015): 16-182, diakses 5 Januari 2017, doi: http://dx.doi.org/10.21580/nw.2015.9.2.521.

Tibi, Bassam. Islamism and Islam. London: Yale University Press, 2012, PDF ebook, bab 5.

. "Religious extremism or religionization of politics? The Ideological foundations of political Islam". dalam Radical Islam and International Security, Hillel Frisch dan Efraim Inbar, 11-37. London: Routledge, 2008. PDF e-book, bab 1.

Turmudi, Endang. Islam dan Radikalisme di Indonesia. Jakarta: LIPI Press, 2005.

Undang-undang Nomor 20 Tahun 2003, Sistem Pendidikan Nasional, Pasal 1 butir 19.

Wiles, Jon \& Joseph Boundi. Curriculum Development: A Guide to Practice, fourth edition.New York: Macmillan Publishing Company, 1993. 